\title{
LA LEXICOGRAFÍA ESPAÑOLA EN EL SIGLO XIX: DEL DICCIONARIO A LA ENCICLOPEDIA
}

\author{
DOLORES AzORÍN FERNÁNDEZ \\ (Universidad de Alicante)
}

\begin{abstract}
RESUMEN
The main purpose of this article is to provide a general view of the Spanish no academic monolingual lexicography in the nineteenth century.

In order to achieve this objetive, we have started showing the different causes of its unexpected apperance in the begginning of this century and also, specially, the reasons of its subsequent evolution towards the encyclopedic Dictionary model.
\end{abstract}

Nuestro acercamiento a la historia de la lexicografía española se centra en un periodo muy poco conocido de su desarrollo: el siglo XIX ${ }^{1}$.Época especialmente prolífica por lo que al cultivo de la vertiente monolingüe se refiere. Baste recordar, a título de ejemplo, que 10 de las 21 ediciones del DRAE (Diccionario de la Real Academia Española) verán la luz en esta centuria² y que, en contraste con lo acaecido en otras etapas, la labor de la Academia Española será revisada por un extenso grupo de autores particulares, que presentan sus obras como alternativa a la norma dictada por la docta corporación.

1 Sobre el periodo que nos ocupa es imprescindible la consulta del trabajo de $\mathrm{M}$. Seco $« \mathrm{El}$ nacimiento de la Iexicografía española no académicas, Estudios de lexicografía española, Madrid, Paraninfo, 1987, pp. 129-151. Véase también el trabajo de Rosario Baquero, «Notas en contribución a la historia de la lexicografía española monolingüe del siglo XIX», Actas del IV Congreso Internacional de EURALEX, Barcelona, Biblograf, 1992, pp. 455-461. Véase, asimismo, Ana María Bueno Morales, La lexicografía monolingüe no académica del Siglo XIX, Tesis de Doctorado, dirigida por el Dr. M. Alvar Ezquerra, defendida en la Universidad de Málaga, Curso 1995-1996. (inédita). También de la misma autora, el artículo «La lexicografía no académica del siglo XIX: cl Diccionario Enciclopédico de la lengua española publicado por la editorial Gaspar y Roig, en M. Alvar Ezquerra (Coord.), Estudios de historia de la lexicografía del español, Málaga, Universidad de Málaga, 1996, pp. 151-157.

2 Son estas las comprendidas entre la cuarta y la décimo tercera, publicadas sucesivamente en $1803,1817,1822,1832,1837,1843,1852,1869,1884$ y 1899. 
A este grupo pertenecen, entre otros de menor importancia, los diccionarios de Núñez de Taboada (1825), Pla y Torres (1826), Peñalver (1842), Labernia (1844), Salvá (1846), Domínguez (1846-47), Castro (1852), Gaspar y Roig (1853) y Sociedad Literaria $(1853)^{3}$.

No deja de ser insólito que, después de más de cien años de exclusivismo académico - roto tan sólo por el paréntesis de Terreros y $\mathrm{Pando}^{4}$ - la lexicografía monolingüe castellana renazca con tan inusitada profusión.

El surgimiento de este fenómeno tiene en su origen, una sencilla justificación comercial propiciada, sin duda, por determinadas circunstancias políticas y culturales que concurren en el proceso. Así, para Manuel Seco:

Los primeros pasos en esta dirección se habían dado cuando (...) los editores franceses descubrieron las posibilidades que les brindaba el mercado de las recién emancipadas colonias españolas de América - roto el comercio de ellas con España-, así como la inestimable colaboración de la propia metrópoli al suministrarles suficiente número de intelectuales exiliados útiles para desempeñar la necesaria tarea redactora ${ }^{5}$.

3. La referencia completa de estas obras es la siguiente:

-M. Núñez de Taboada, Diccionario castellano, París, Seguin, 1825.

-C. Pla y Torres, Diccionario de la Lengua Castellana por la Academia Española, París, Librería de Cormon y Blanc, 1826.

-J. Peñalver, Panléxico. Diccionario Universal de la Lengua Española, Madrid, Imprenta de Ignacio Arboix, 1842.

-V. Salvá, Nuevo Diccionario de la lengua Castellana, París, Fournier, 1846.

En 1838, Salvá había publicado, con algunas correcciones suyas, la octava edición del DRAE (1837), que salió a la luz con el título siguiente: Diccionario de la Lengua Castellana por la Academia Española, reimpreso de la octava edición publicada en Madtid en 1837, con algunas mejoras por D. Vicente Salvá, París, Smith, 1838. Esta obra volverá a editarse en 1841. Sin embargo, la contribución original de Salvá a la lexicografía española es el Nuevo Diccionario arriba reseñado.

-R.J. Dominguez, Diccionario Nacional o Gran Diccionario Clásico de la Lengua Española, Madrid, Bernat, 1846-47.

-A. de Castro, Gran Diccionario de la Lengua Castellana, Madrid, Semanario Pintoresco Español y de la llustración, 1852. 1853-1855.

-Diccionario Enciclopédico de la Lengua Española, Madrid, Editorial Gaspar y Roig,

- Nuevo Diccionario de la Lengua Castellana, París, Rosa y Bouret, 1853.

4 En efecto, el monopolio de la Real Academia Española en el terreno de la lexicografía monolingüe, iniciado en 1726 con la aparición del primer volumen del Diccionario de Autoridades, sólo se verá interrumpido con ocasión de la publicación póstuma del Diccionario Castellano con las voces de ciencias y artes del jesuíta Esteban de Terreros y Pando, Madrid, 1786-93. (Véase la edición facsímil de este Diccionario a cargo de M. Alvar Ezquerra, Madrid, Arco-Libros, 1987. Véase especialmente, la «Presentación» que aparece al frente de la mencionada edición, pp. 5-16, recogida también en M. Alvar Ezquerra, La lexicografia descriptiva, Barcelona, Biblograf, 1993, pp. 249-259. 
En efecto, son los editores del país vecino quienes darán comienzo a esta aventura lexicográfica, que tiene como objetivo primordial satisfacer la demanda del público hispanohablante del otro lado del Atlántico. El propio Andrés Bello, en una carta dirigida a Mendíbil, fechada en Santiago de Chile en 1831, daba cuenta de la situación de creciente demanda de bienes de cultura que se estaba produciendo en los países de Iberoamérica, viniendo a corroborar la existencia de ese amplio mercado que allí se abría para los editores europeos:

Entre las innumerables faltas y privaciones a que estamos condenados en csta parte del mundo —escribe Bello - no es la menos persistente y perjudicial la de libros útiles y elementales para la instrucción de la juventud (...) Yo he propuesto al gobierno como medio de suplir esta falta, el de hacer traducir c imprimir en Europa las obras modernas más acreditadas (...) y he creído que pudiera convenir a algunos de los españoles emigrados que hay en París y Londres, entre los cuales sé que los hay de mucha instrucción y que manejan la lengua patria con la corrección y pureza necesaria, cl encargarse de este trabajo.

Respondiendo al llamamiento el gramático venezolano, Vicente Salvá, algunos años más tarde, destinó su Nuevo Diccionario de la Lengua Castellana a los lectores de hispanoamérica, a quienes rinde obligado homenaje en la «Introducción», agradeciendo la acogida dispensada a sus anteriores publicaciones. La inclusión masiva de americanismos que ofrece Salvá en su Diccionario — sin precedentes $^{7}$ en la historia de la lexicografía española- es, sin duda,el mejor homenaje que el filólogo valenciano podía hacerles:

Entre las dicciones olvidadas por la Academia en su Diccionario escribe Salvá-, debieron llamar mi particular atención desde que me propuse adicionarlo las peculiares de América, porque se hacía más notable la sinrazón de excluirlas en una obra destinada principalmente a ella. Y aún podía tachárseme de ingrato, si no aprovechaba esta coyuntura de corresponder a la singular preferencia con que ha acogido cuantos libros he publicado ${ }^{*}$.

Como hemos podido comprobar, la lexicografía extra-académica del XIX contó, en efecto, con la colaboración de los intelectuales españoles exiliados y

5 M. Seco, «El nacimicnto de la lexicografía española no académica», ed. cit., p. 130.

" Texto citado por Margarita Lliteras, «Estudio introductorio» a su edición de la Gramática castellana de Vicente Salvá, Madrid, Arco-Libros, 1988, pp. 17-18.

7 Para los americanismos en el Diccionario de Salvá, véasc: D. Azorín y R. Baquero, «Los americanismos en el Nuevo Diccionario de la Lengua Castellana de Vicente Salvá», Actas del II Congreso Internacional de Historia de la Lengua Española, T. 1, Madrid, Arco-Libros, 1992, pp. 963-970.

\& Vicente Salvá, «Introducción del adicionador», en Nuevo Diccionario de la Lengua Castellana, ed. cit., p. XXVII. 
también, como sugiere M. Seco" con el concurso indirecto de la Academia Española que proporcionó no sólo el texto de su Diccionario, compendio matriz sobre el que fueron confeccionados todos estos repertorios, sino también su prestigio como institución. Recordemos que el nombre de la ilustre corporación fue estampado sin recato alguno en las portadas de muchos diccionarios de la época, más a modo de reclamo publicitario que como declaración intencionada de fuentes.

Podemos concluir, a la vista de lo expuesto, que si el origen de la lexicografía académica, en los albores del siglo XVIII, lo encontramos en el patriótico empeño del reducido grupo de intelectuales que lideró el Marqués de Villena; el origen del movimiento que nos ocupa estuvo presidido por intereses prioritariamente comerciales. Este hecho, que marcaría hasta cierto punto la calidad de sus logros, no llegó a impedir del conjunto surgieran obras de indudable mérito. Pero, lo más importante del caso fue la instauración, por primera vez en España, de un incipiente pluralismo en la producción de diccionarios que, finalmente, traería como consecuencia el ensayo de nuevas formas de concebir el diccionario de la lengua.

Muchas de las obras que se incluyen en este período se limitaron a reproducir, con añadidos de poca monta, la edición vigente del Diccionario de la Academia. Otros, aunque modestamente, superarían el caudal del DRAE con incorporaciones que suponen ya la existencia de planteamientos diferenciados respecto del modelo propugnado por la corporación española. Este será el caso, por ejemplo, del inaugurador de la corriente que estudiamos, Manuel Núñez de Taboada, en el que se detecta ya cierto giro hacia lo sincrónico-descriptivo como criterio para la selección del léxico, frente a la opción más normativa que informa al texto académico. Buena parte de las voces que Taboada incorpora a la sexta edición del Diccionario académico, que es la que le sirve de base, proceden, como demostró $\mathrm{R}$. Baquero, de la lengua común, del estilo familiar o, son tecnicismos de reciente incorporación al acervo idiomático general ${ }^{10}$.

El criterio restrictivo que mantuvo la Academia respecto de la incorporación de voces técnicas se va a convertir, en esta época, en uno de los principales

" Cfr. M. Seco, «El nacimiento..», cit., p. 150, para quien «Todos los diccionarios sin excepción se basan en el léxico académico».

11. Según R. Baquero -que utiliza como muestra la totalidad de la letra A-, Núñez de Taboada añadió 207 voces de nuevo cuño al texto académico. De éstas, 163 son de la lengua general (sin acotación de nivel de lengua), 37 son voces técnicas y 7 pertenecen al uso familar. Recordemos que, según el propio Núñez de Taboada declara en el «Prefacio» de su Diccionario: «...mi diccionario se halla aumentado con cerca de 5.000 voces de que carece el de la Real Academia Española, y que he sacado de su propio caudal y de los autores nacionales más clásicos» (ed. cit., p. II). Estas voces se localizan fácilmente en el texto al ir precedidas por la marca del asterisco; pero, según nuestros cálculos no del todo exactos, la cifra que señala el autor está notablemente «hinchada», pues creemos que no sobrepasa las tres mil entradas. 
defectos que los lexicógrafos particulares achacan al Diccionario oficial. Esta carencia será esgrimida, en numerosas ocasiones, como uno de los motivos que da pie a sus respectivas revisiones del texto académico. Pues, en efecto, ya en el «Prólogo» del Diccionario de Autoridades, manifiesta la recién creada corporación cuál es su parecer en este punto:

De las voces propias pertenecientes a Artes liberales y mechánicas ha discurrido Ia Academia hacer un Diccionario separado, quando este se haya concluído: por cuya razón se ponen solo las que han parecido mas comunes y precisas al uso, y se podían echar menos ${ }^{11}$.

Este principio se mantendrá en las sucesivas ediciones del Diccionario «vulgar», pese a las reiteradas críticas que la Academia hubo de soportar. Así, en la novena edición del DRAE (1843), la corporación justificaba su postura restrictiva con los siguientes argumentos:

Pero hay también una inmensa nomenclatura de las ciencias, artes y profesiones, cuyo significado deben buscar los curiosos en los vocabularios particulares de las mismas: tales voces pertenecen a todos los idiomas y a ninguno de ellos; y si hubieran de formar parte del Diccionario de la lengua común, lejos de ser un libro manual y de modesto precio, circunstancias que constituyen su principal utilidad, sería una obra voluminosa en demasía, semienciclopédica y de difícil adquisición y manejo ${ }^{12}$.

El razonamiento de la Academia en este punto no carece de lógica: un diccionario normativo debe registrar la lengua culta común, de la que también forman parte los tecnicismos siempre y cuando hayan traspasado los límites de su estricta especialidad y se haya generalizado su uso. Por otro lado, la progresiva difusión en la comunidad internacional de los descubrimientos científicos, empieza a provocar la subsecuente internacionalización de los términos que se emplean para designarlos, que por ello «...pertenecen a todos los idiomas y a ninguno de ellos». Sin embargo, la Academia no siempre estuvo a la altura de sus manifestaciones programáticas y, en el terreno de los tecnicismos fue más bien a la zaga, desacompasada del discurrir del idioma que, naturalmente, seguía evolucionando a despecho del criterio de la docta corporación ${ }^{13}$.

11 Real Academia Española, «Prólogo» al Diccionario de Autoridades, Madrid, 1726, p. V. Citamos por la edición facsímil, Madrid, Gredos, 1963. Como es sabido, la Academia nunca llevó a cabo el proyecto de redacción de un Diccionario especial que recogiera las voces científicas y técnicas, aunque ese fuera su propósito en aquel momento. 1843, p. I.

12 Real Academia Española, «Prólogo» al Diccionario de la Lengua Castellana, Madrid,

13. Sobre el problema de la inclusión de Ios tecnicismos en el Diccionario de la Real Academia, vid. el trabajo de Manuel Alvar López, «El caminar del Diccionario académico», Actas del IV Congreso Internacional de la European Association for Lexicography, Barcelona, Biblograf, 
Como hemos señalado arriba, Nuñez de Taboada incorporó a su revisión de la $6^{\text {a }}$ edición del DRAE una cantidad considerable de voces técnicas y, más adelante, Vicente Salvá abundaría aún más en esta dirección, no sin antes criticar abiertamente en la «Introducción» de su obra el equívoco proceder de la Academia:

¿Cómo puede explicarse que la Academia - afirma Salvá- nos dé como corrientes millares de voces anticuadas, al paso que deja de admitir las que todo el mundo conoce y usa?. ¿Qué razón puede asignarse, para que el diccionario no se halle, en punto de ciencias y arte, no diré al nivel de los conocimientos de los Académicos, lo cual sería sobrado pedir, sino a la par de los progresos comunes y generalizados? ${ }^{14}$

Según el recuento realizado por nosotros sobre la letra A de los Diccionarios de Taboada y Salvá, sabemos que el primero incorporó a la sexta edición del DRAE 36 voces $^{15}$ expresamente marcadas como tecnicismos; mientras que Salvá, veinte años después, introdujo hasta $119^{16}$ términos de especialidad en la misma letra, todos ellos ausentes de la novena edición del Diccionario académico.

El camino emprendido por Núñez de Taboada, Salvá y otros lexicógrafos, como Adolfo de Castro, daría paso seguidamente al ensayo de un nuevo género lexicográfico que, aunque fundado en modelos extranjeros principalmente ${ }^{17}$, vino a encontrar su justificación en el parco tratamiento que el texto académico otorgaba al léxico científico y técnico: nos estamos refiriendo a los diccionarios

1992, pp. 10-12. Cfr. también M. Alvar Ezquerra, «El Diccionario de la Academia a través de sus prólogos», en La lexicografía descriptiva, Barcelona, Biblograf, 1993, pp. 229-230.

14 Vicente Salvá, «Introducción del Adicionador», Nuevo Diccionario de la Lengua Castella. na, ed. cit., p. VIII.

15. Recogemos a continuación dichas voces con su respectiva marca de especialidad:

Alvitana (Agricultura), Aductor (Anatomía), Acrónico-ca (Astronomía), Amade (Blasón), Antera, Acopada, Arundináceas, Arvense (Botanica), Aislador (Física), Atentatorio-ria (Forense), Acutangular (Geometría), Amorfo-fa (Historia natural), Aculebrar, Andanada, Aparcadura (Marinería), Acracia, analéptico, Arenación, Asfixia (Medicina), Acorde, Arpegio (Música), Afelpar, Agalibar, Agolar, Ahorcaperro, Aljadrez, Asocar, Atrozar, Avitualla, Ayustar, Ayuste, Azambogo (Náutica), Alecto, Argentino-na (Política), Agallato (Química), Anáfora (Retórica).

${ }_{16}$ Con el fin de no recargar el aparato crítico, ofrecemos, en el apéndice que cierra este artículo, el listado alfabético de voces técnicas introducidas por Salvá en la letra A de su Nuevo Diccionario.

17 Como ha señalado Manuel Seco, el primer cultivador del género enciclopédico en España, Ramón Joaquín Domínguez, sigue «..en esta atención preferente al léxico técnico, las huellas de Terreros, cuyo diccionario se titulaba Diccionario castellano con las voces de ciencias y artes; y, más aún que su modelo, no queda exento de la sospecha de que una parte de sus materiales no está recogida directamente del uso español, sino del testimonio de la lexicografía extranjera, en la idea -no desacertada - de la progresiva internacionalización del lenguaje científico (M. Seco, «Ramón Joaquín Domínguez», Estudios de lexicografía española, ed. cit., p. 159). En efecto, el modelo que utiliza Domínguez para elaborar su obra, como ha demostrado también M. Seco, es el Dictionnaire national ou grand dictionnaire critique de la langue française. París, 1843, de L.N. Bescherelle, al que nuestro lexicógrafo imitaría hasta en el título de la obra, y no la obra del jesuíta Terreros y Pando aunque éste, en cierto sentido, pueda considerarse como el inspirador de la lexicografía extraacadémica de este período. 
enciclopédicos, modadidad que también tuvo su origen en este período en la obra de Ramón Joaquín Domínguez ${ }^{18}$. Su diccionario (1846-47) alcanzó un éxito sin precedentes en la historia de la lexicografía española: diecisiete ediciones hasta 1889 , según los datos allegados por Manuel $\operatorname{Seco}^{19}$, lo que viene a confirmar la existencia de un amplio mercado en nuestro país para esta modalidad lexicográfica.

Esa decantación hacia el enciclopedismo, que pasa por el acopio masivo de saberes diversos, la podemos detectar en el afän acumulativo presente ya en los diccionarios de lengua anteriores a Domínguez. En el siguiente cuadro comparativo, basado en una pequeña muestra de la letra $\mathrm{A}^{20}$, elegida al azar, se observa cómo, desde Núñez de Taboada hasta Adolfo de Castro, hay una clara tendencia a incrementar, por vía de las voces de especialidad, el componente enciclopédico de los diccionarios generales de la lengua:

Lema

Marca

Taboada

DRAE Salvá

Castro

Domíng 1825 1843 1846 1852 1846-7

$\begin{array}{lllllll}\text { Apacaro } & \text { bot } & - & - & - & - & + \\ \text { Apaches } & \text { geog } & - & - & - & - & + \\ \text { Apagapenol naut } & + & + & + & + & + \\ \text { Apagar 1 } & \text { pint } & + & + & + & + & + \\ \text { Apagar 2 } & \text { naut } & - & - & - & + & - \\ \text { Apagar 3 } & \text { naut } & - & - & - & + & - \\ \text { Apagarse 1 } & \text { naut } & - & - & - & + & - \\ \text { Apagarse 2 } & \text { mus } & - & - & - & + & - \\ \text { Apagma } & \text { cir } & - & - & - & - & + \\ \text { Apagavela 1 naut } & - & - & - & + & - \\ \text { Apagavela 2 } & \text { naut } & - & - & - & + & -\end{array}$

18 Sobre la vida y la producción lexicográfica de Domínguez, véanse: M. Seco, «Ramóm Joaquín Dominguez», art. cit., pp. 152-164 y «La definición lexicográfica subjetiva», Estudios de lexicografía española, ed. cit., pp. 165-177.

10 Cf. la nota 20 de M. Seco en su estudio «Ramón Joaquín Domínguez», cit., p.157.

21) La muestra que presentamos incluye todos los lemas que comienzan con la combinación Apa-. Cuando una voz presenta varias acepciones, lo hacemos constar mediante la numeración consecutiva de las mismas. Las abreviaturas que figuran en la casilla «Marca», son las que se utilizan comúnmente en estos diccionarios. 


$\begin{array}{lllllll}\text { Apagogia } & \text { lóg } & - & - & - & - & + \\ \text { Apaisado } & \text { pint } & - & - & - & + & + \\ \text { Apalancha } & \text { med } & - & - & - & - & + \\ \text { Apalachina } & \text { bot } & - & - & - & - & + \\ \text { Apalaje } & \text { med } & - & - & - & - & + \\ \text { Apalmada } & \text { blas } & + & + & + & + & + \\ \text { Apalato } & \text { bot } & - & - & - & - & + \\ \text { Apalear } & \text { agr } & - & - & - & - & + \\ \text { Apalitro-a } & \text { entom } & - & - & - & - & + \\ \text { Apalo } & \text { entom } & - & - & - & - & + \\ \text { Apalodermo } & \text { ornit } & - & - & - & - & + \\ \text { Apamea } & \text { hist } & - & - & - & - & + \\ \text { Apantismo } & \text { med } & - & - & - & - & + \\ \text { Aparadura } & \text { naut } & + & - & - & + & - \\ \text { Aparar 1 } & \text { artill } & - & - & - & - & + \\ \text { Aparar 2 } & \text { naut } & - & - & - & + & + \\ \text { Aparasolado } & \text { bot } & + & + & + & + & + \\ \text { Aparato 1 } & \text { cir } & - & - & - & - & + \\ \text { Aparato 2 } & \text { fisiol } & - & - & - & - & + \\ \text { Aparato 3 } & \text { quim } & - & - & - & - & + \\ \text { Aparctias } & \text { naut } & - & - & - & - & + \\ \text { Aparejador } & \text { arq } & - & - & - & + & + \\ \text { aparejador } & \text { naut } & - & - & - & + & + \\ \text { Aparejamiento } & \text { naut } & - & - & - & - & + \\ \text { Aparejar 1 } & \text { naut } & + & + & + & + & + \\ \text { Aparejar 2 } & \text { naut } & - & - & - & + & - \\ \text { Aparejar 3 } & \text { pint } & + & + & + & + & + \\ \text { Aparejar 4 } & \text { dorad } & - & - & - & - & + \\ \text { Aparejar 5 } & \text { carp } & - & - & - & - & + \\ \text { Aparejo 1 } & \text { naut } & + & + & + & + & + \\ \text { Aparejo 2 } & \text { naut } & - & - & - & - & + \\ \text { Aparejo 3 } & \text { naut } & + & + & + & + & - \\ \text { Aparejo 4 } & \text { naut } & - & - & - & + & - \\ \text { Aparejo 5 } & \text { naut } & - & - & - & + & - \\ \text { Aparejo 6 } & \text { pint } & + & + & + & + & - \\ \text { Aparejo 7 } & \text { min } & - & - & - & + & - \\ \text { Aparejos 1 } & \text { pint } & - & - & - & + & - \\ \text { Aparejos 2 } & \text { pesca } & - & - & - & + & - \\ \text { Apargia } & \text { bot } & - & - & - & - & + \\ \text { Aparina } & \text { bot } & - & - & - & - & +\end{array}$




\begin{tabular}{|c|c|c|c|c|c|}
\hline Aparismio & bot & - & - & - & 一 \\
\hline Apartador & $\operatorname{agr}$ & - & - & - & - \\
\hline Apartamiento 1 & 1 fort & + & + & + & + \\
\hline Apartamiento 2 & 2 naut & - & - & 一 & + \\
\hline Apartamiento 3 & 3 arq & - & - & - & + \\
\hline Apartar 1 & for & + & + & + & - \\
\hline Apartar 2 & mont & - & - & - & + \\
\hline Apartrosis & anat & - & - & 一 & 一 \\
\hline Aparvadero & agr & - & - & + & - \\
\hline Aparvar & agr & - & - & - & - \\
\hline Apanojado & bot & - & — & + & - \\
\hline Apata & bot & - & - & - & - \\
\hline Apatelo & entom & - & - & - & - \\
\hline Apatía & $\operatorname{med}$ & - & - & - & - \\
\hline Apaticos & zool & - & - & - & - \\
\hline Apatitie & bot & - & - & - & - \\
\hline Apatito & $\min$ & - & - & - & - \\
\hline Apato & entom & - & - & - & - \\
\hline Apaturea & entom & - & - & - & - \\
\hline
\end{tabular}

$\begin{array}{llllll}\text { TOTAL } & 13 & 12 & 14 & 30 & 50\end{array}$

Los datos que se desprenden del cuadro comparativo anterior vienen a confirmar la tendencia - muy marcada en Castro $^{21}$ - a superar el caudal de tecnicismos del Diccionario académico que presentan los diccionarios de este período. Aunque apenas hay diferencias entre los tres primeros, es significativo que en un tramo tan pequeño, Salvá supere a la Academia en dos acepciones diatécnicas y Núnez de Taboada en una.

Esta tendencia acabaría concretándose en el género híbrido del Diccionario enciclopédico tal y como lo concibió Domínguez. A las numerosas ediciones de este Diccionario hay que sumar las que tuvo también el Diccionario enciclopé-

21 El Diccionario de Adolfo de Castro, del que sólo se publicaría el primer tomo, es, en realidad, una obra atípica en este momento. Planteado como diccionario de lengua, su afán extensivo lo convierte en un «Tesoro de la Lengua» que pretende abarcar todas las modalidades y subsistemas del español. El título completo de la obra ilustra perfectamente sobre su contenido: Gran diccionario de la lengua española...Contiene las voces admitidas en el trato común. las anticuadas, las más usadas en todas las ciencias, en todas las artes y en todos los oficios, todas las maritimas, las de las Américas Españolas, las de Filipinas, los proverbios, las noticias de personajes proverbiales y las maneras de decir más elegantes de nuestros buenos escritores, asi en el género culto como en el picaresco. todo comprobado con las autoridades correspondientes en prosa y verso. 
dico de la lengua española(1853-55) de la editorial Gaspar y Roig, ${ }^{2 ?}$ que trajo como novedad la autoría compartida por un grupo de redactores, coordinados por Eduardo Chao. No faltó, en esta ocasión tampoco, la aparición del descarado oportunismo de quienes se aprovechan del trabajo y del éxito ajenos: en 1853 salió a la luz el Nuevo diccionario de la lengua española por una Sociedad Literaria, publicado en París por la editorial Rosa y Bouret. Obra que no solo se benefició del renombre de Domínguez, sino que lo plagió casi al pie de la letra, copiando incluso las mordaces críticas que aquel dirigió contra la Academia, uno de los «blancos» preferidos del malogrado Domínguez ${ }^{23}$. Sirva como muestra del nada ortodoxo proceder de esta Sociedad Literaria el artículo que dedica al verbo Acuchillar, idéntico al de Domínguez, inluso en el comentario irónico:

Acuchillar: v.a. Dar cuchilladas, pasar a cuchillo// ant. Matar a cuchillo (Acad.) Matar a cuchillo debe ser tan antiguo como el mundo; pero no es verbo que haya caducado sino en sentir de nuestros doctos académicos.

Entre las muchas novedades que en el terreno lexicográfico trajo consigo el siglo XIX, la aparición del diccionario enciclopédico es, quizás, una de las más relevantes desde el punto de vista comercial. El diccionario enciclopédico, dirigido fundamentalmente al gran público, se ofrecía como instrumento polivalente, compendio de todos los saberes - incluido el idiomático-y, por lo tanto, sustituto de otros compendios más especializados -incluido el diccionario de la lengua-. Ese hibridismo que a los lectores más exigentes podría repugnar, ha constituido, al parecer, la clave del éxito de estas obras cuya utilidad es, por otro lado, incontestable. Según M. Seco:

Siguiendo el ejemplo del gran Terreros en el siglo anterior, se decide dar paso al tecnicismo de las ciencias, de las artes y de los oficios, y, a imitación de la corriente lexicográfica francesa, surge el ideal del diccionario acumulativo (ideal aún hoy muy vivo en la opinión vulgar), de donde nace la aclimatación entre nosotros, de la mano de Domínguez, del género diccionario enciclopédico, que tanta boga alcanzará a partir de los últimos años del siglo y que hoy continúa en plena pujanza ${ }^{24}$.

22 Recientemente, se ha ocupado de este diccionario Ana $\mathrm{M}^{\mathrm{a}}$ Bueno Morales, «La lexicografía no académica del siglo XIX: el Diccionario enciclopédico de la lengua española publicado por la editorial Gaspar y Roig», en M. Alvar Ezquerra (Coord.), Estudios de historia de la lexicografía del español, Málaga, Universidad de Málaga, 1996, pp. 151-157.Vid. concretamente las págs. 153-154 donde la autora da cuenta de las ediciones de que fue objeto esta obra.

2.3 Cf. Ios artículos de Seco, «Ramón Joaquín Domínguez» y «La definición lexicográfica subjetiva: el diccionario de Domínguez», en Estudios de lexicografía española, ed. cit.

24 M. Seco, «El nacimiento de la lexicografía moderna no académica», Estudios de lexicografia española, cit., p. 150. 


\section{APÉNDICE}

\section{RELACIÓN ALFABÉTICA DE VOCES DE ESPECIALIDAD AÑADI- DAS POR VICENTE SALVÁ A LA LETRA «A» DE LA NOVENA EDICIÓN DEL DRAE}

$\begin{array}{ll}\text { Abanderar, naut } & \text { Alimentario-a, for } \\ \text { Abarloar, naut } & \text { Alopecio-cia, med } \\ \text { Abitar, mar } & \text { Abiton, mar } \\ \text { Altear, naut } & \text { Alterante, med } \\ \text { Acantabola, cir } & \text { Aludel, quim } \\ \text { Acataléctico-ca, poét } & \text { Alunamiento, mar } \\ \text { Acelajarse, naut } & \text { Alunar, mar } \\ \text { Aceptilación, for } & \text { Alvino-na, med } \\ \text { Acerval, lóg } & \text { Alzador, impr } \\ \text { Acetato, quim } & \text { Amachambrar, cant } \\ \text { Acintillado-da, bot } & \text { Amarinar, naut } \\ \text { Acoderar, mar } & \text { Amariposado-da, bot } \\ \text { Acollador, naut } & \text { Amentáceo-cea, bot } \\ \text { Acores, med } & \text { Amisible, teol } \\ \text { Acornado-da, blas } & \text { Analogismo, dial } \\ \text { Acrupido-da, blas } & \text { Ancorel, mar } \\ \text { Actitadero-ra, for } & \text { Anegado-da, mar } \\ \text { Actitar, for } & \text { Anfismilo, cir } \\ \text { Actora, for } & \text { Anginoso-sa, med } \\ \text { Aculado-da, blas } & \text { Antapoca, for } \\ \text { Aculebrarse, agr } & \text { Antecanto, poét } \\ \text { Acutangular, geom } & \text { Anteespolón, arq } \\ \text { Achique, naut } & \text { Antefoso, fort } \\ \text { Acho, naut } & \text { Anteojada, naut } \\ \text { Achubascarse, naut } & \text { anticresis, jur } \\ \text { Adámico-ca, mar } & \text { Apanojado-da, bot } \\ \text { Adir, for } & \text { Aparvadero, agr } \\ \text { Adjudicatatio-ria, for } & \text { Apezonado-da, bot } \\ & \end{array}$


Aducción, anat

Aductores, anat

Aferravelas, mar

Afogonadura, mar

Afoscarse, mar

Afrodisíaco, med

Afta, med

Afuscarse, mar

Agraja, aqu

Agripa, cir

Agrupado, pint

Aguacharse, agr

Ahocicar, naut

Ahorcaperro, mar

Ajel, manej

Alargada, naut

Alargadera, quim

Alargadura, naut

Albarsa o albarza, mar

Albuco, med

Alcalescencia, quim

Alcalescente, quim

Alcalización, quim

Alcalizar, quim

Aleatorio-ria, med

Alexitérico-ca, med

Atemporalado-da, naut

Aterrada, mar

Aterraje, mar

Atierre, min

Atoaje, mar
Apiri, min

Aplacelado-da, naut

Aplacerado-da, naut

Apogear, astron

Apopar, mar

Apóstola, teol moral

Arenación, med

Argema, med

Arrambaje o arramblaje, mar

Arrambar o arramblar, mar

Arrancado-da, blas

Arrastradera, naut

Arriadura, naut

Arricete, naut

Artrítico-ca, med

Arundináceo-cea, bot

Arvense, bot

Ascórides, med

Ascios, geogr

Aseguramento, com

Asenglar, naut

Asocairarse, naut

Asocar, mar

Asperarteria, anat

Asurcado-da, bot

Ateje, bot

Atonía, med

Aturbonarse, naut

Auscultación, med

Auscultar, med

Avalizar, naut

Azpillera, naut 